Original Research Paper

\title{
Correlations between Growth and Yield Parameters of Soybean (Glycine max (L.) Merr.) under the Influence of Bradyrhizobium japonicum in Kipushi (The Democratic Republic of Congo)
}

\author{
${ }^{1}$ Ben Tshibuyi Kasu-Bandi, ${ }^{3}$ Laurent Kidinda Kidinda, ${ }^{2}$ Germain Nyembo Kasendue, \\ ${ }^{3,4}$ Louis Baboy Longanza, ${ }^{3}$ Kasongo Lenge Emery and ${ }^{3,5}$ Antoine Kanyenga Lubobo \\ ${ }^{I}$ National Institute for Agricultural Research and Study (INERA), Kipopo Station, P.O Box 224; Lubumbashi, DR Congo \\ ${ }^{2}$ Agricultural Economics, Faculty of Agricultural Sciences, University of Kinshasa, P.O Box 117, Kinshasa XI, DR Congo \\ ${ }^{3}$ Faculty of Agricultural Sciences, Université de Lubumbashi, Lubumbashi, DR Congo; P.O Box 1825 \\ ${ }^{4}$ Scientic Collaborator at Université Libre de Bruxelles, Inter-Faculty School of Bioengineers, Landscape Ecology Service and \\ Crop Production Systems, P.O Box 1050 Brussels, Belgium \\ ${ }^{5}$ International Center for Tropical Agriculture, Harvest Plus, DR Congo
}

Article history

Received: 01-12-2018

Revised: 18-01-2019

Accepted: 16-08-2019

Corresponding Author:

Ben Tshibuyi Kasu-Bandi,

National Institute for

Agricultural Research and

Study (INERA), Lubumbashi,

DR Congo

Email: bentshibuyi@yahoo.fr

\begin{abstract}
This study aimed to evaluate the correlations between different agronomic parameters and their contribution to soybean performance under Bradyrhizobium japonicum influence. The experiment was carried out at Kanyameshi (Kipushi), following a Split Plot design, with three strains of Bradyrhizobium japonicum (GraphExTM, Bradyrhizobium sp and Sojapak (B) 50) and four soybean varieties (TGX 1740-7F: V1, PAN 1867: V2, TGX 1880-3E: V3 and LUKANGA: V4). The strongest correlations were obtained between fresh biomass and plant height, the number of stems and collar diameter, fresh biomass and collar diameter, number of stems and plant height, number of roots and number of stems, fresh biomass and number of roots, number of pods and number of leaves. The collar diameter is the most positively correlated parameter with both growth and soybean yield parameters. While lifting rate, collar diameter, plant height, number of stems, number of leaves, fresh biomass, number of nodules and number of pods are the most linked to soybean grain yield. A significant negative correlation was observed between number of leaves and the weight of $100 \mathrm{~g}$. Fresh biomass was found to be more predictable, whereas number of leaves is the growth parameter that contributes most to soybean fresh biomass. Based on their decreasing contribution to fresh biomass, the various parameters can be classified as follows: Number of leaves $>$ number of root>plant height> collar diameter. Among examined agronomic parameters, only four contribute directly to the soybean yield, namely number of leaves, number of pods, fresh biomass and collar diameter. By applying Bradyrhizobium japonicum to the four soybean varieties, the correlations between observed parameters were enhanced. This study is a major contribution in the conduct of soybean cultivation as it identified the parameters on which the farmer should focus to maximize soybean grain yield.
\end{abstract}

Keywords: Agronomic Parameters, Soybean Yield, Correlations

\section{Introduction}

Soybean (Glycine max (L.) Merr.) is one of the most important and widely grown crops in the world. It accounts for $30 \%$ of the world's processed vegetable oil (Graham and Vance, 2003) and provides to the body a range of unsaturated fatty acids important for vitamin intake (Mandimba, 1997; Javaheri and Baudoin, 2001; Javaheri and Baudoin, 2001; Giller and Dashiell, 2007). 
Due to multiple constraints, soybean yield is very low in most cropping conditions in Africa. The national average yield varies from one country to other; in DR Congo, it was estimated at 0.56 t. ha $\square 1$ in 2014 against to $2.1 \mathrm{t}$. ha $\square 1$ in Zambia (FAO, 2017). A large literature is devoted to the issue through research-based solutions (Hungry and Bohrer, 2000; Hardarson and Broughton, 2003; Amin et al., 2008; Tshibuyi and Kidinda, 2015), the establishment of appropriate strains in specific local conditions (e.g. Bruno et al., 2003; Ferguson et al., 2006; Abaidoo et al., 2007; Ben Tshibuyi and Kidinda, 2015), nitrogen and phosphate fertilization (e.g., Fatima et al., 2007), organic fertilization (e.g., Kasongo et al., 2013) and optimization of planting date (e.g. Baboy et al., 2015). The results of these studies are reported to improve soybean productivity in many countries.

Despite this progress, several uncertainties remain on the links between the different agronomic parameters influencing the performance of soybeans in the province of Upper Katanga, Democratic Republic of Congo. While the type and nature of the link between two variables are generally determined by studying the correlation coefficients. However, it is established that crop yield is complex and correlation studies alone are insufficient. The correlation coefficient is very important for measuring the degree and direction of linkage of different parameters that affect either positively or negatively the yield (Kumar et al., 2013). The need remains to establish the linear regressions in order to obtain a clear understanding of the contribution of each parameter on the total genetic architecture of the yield. In other parts of the world, this theme is widely discussed (Khan et al., 2000; Amanullah and Hatam, 2001; Peluzio et al., 2005; Chandel et al., 2014; Malik et al., 2011; Mellendorf, 2011; Mbarek et al., 2012; Sokoto et al., 2012; Kuswantoro, 2014; Panda et al., 2015).

The objective of this paper is to highlight the correlations between the different agronomic parameters and the contribution of each parameter on the performance of soybean under Bradyrhizobium japonicum input. The study tries to answer the following questions: (i) what are the types of correlations between the different soybean growth and yield parameters? (ii) what are the most predictable agronomic parameters to soybean yield? (iii) can the contribution of Bradyrhizobium japonicum strengthen correlations among studied agronomic parameters?

\section{Methodology}

\section{Study Area}

The experimentation was carried out at the experimental site of the Institut National pour l'Étude et la Recherche Agronomique (INERA), located at Kaniameshi in Kipushi territory at $11^{\circ} 45^{\prime} 25^{\prime} \mathrm{S}$ and $27^{\circ} 16^{\prime} 59^{\prime}$ E. Kipushi is located in the province of Upper
Katanga in the Democratic Republic of Congo and belongs to the climatic type Cw6 according to Köppen classification. Mean annual temperature varies around $20^{\circ} \mathrm{C}$ (Moulaert, 1992). The average annual humidity is $68 \%$ with monthly moisture levels ranging from a minimum of $47 \%$ in the dry season to a maximum of $86 \%$ during the rainy season.

Recent studies by Mukalay (2016), based on fine and detailed analyzes of soil profiles according to current WRB criteria (WRB: FAO, IUSS, 2014), showed that the Upper Katanga agricultural zone contains four soil groups, including the Acrisols found in Kipushi region.

\section{Conduct of the Experiment}

The experiment was installed using a Split Plot device with three replicates, using three strains of Bradyrhizobium japonicum (GraphExTM, Bradyrhizobium sp and Sojapak $® 50)$ and four soybean varieties (TGX 1740-7F: V1, PAN 1867: V2, TGX 1880-3E: V3 and LUKANGA: V4). The combination of the different strains and varieties resulted in 16 treatments. The planting density was 250000 plants ha $^{-1}$. Soybean seed inoculation was done at planting for concerned treatments. The follow-up of the experiment consisted of three weeding operations at an interval of two weeks from the planting date.

\section{Statistics}

Data from the experiment were submitted to a correlation analysis to determine the Pearson coefficient which defines the nature of the link between two variables. Positively and significantly correlated variables were subjected to linear regression analysis in order to quantify the contribution of each explanatory variable. The influence of Bradyrhizobium japonicum on the correlations between agronomic parameters was evaluated using a Principal Component Analysis (PCA). The correlation matrix, regression and PCR were performed using the Munitab17, Excel and Past software, respectively.

\section{Results}

Table 1 presents the types of correlations between the different soybean growth and yield parameters. It appears that some parameters are either positively or negatively correlated to others. Some positive correlations are significant while others are not. The same observation is made for negative correlations. The strongest correlations are obtained between $\mathrm{FB}$ and $\mathrm{PH}$, NS and CD, FB and CD, NS and PH, NR and NS, FB and NR, NG and NF. This implies that value increase of one of this parameter leads to the increase of the parameter to which it is significantly correlated. In addition, the CD is the most positively correlated with both growth and yield parameters. While the most related to $\mathrm{SY}$ are $\mathrm{LR}, \mathrm{CD}, \mathrm{PH}, \mathrm{NS}, \mathrm{NL}, \mathrm{FB}, \mathrm{NN}$ and NG. 
Table 1: Linear Correlations (Pearson coefficients) between growth and soybean yield parameters. LR: Lifting Rate; CD: Collar Diameter, PH: Plant High, NS: Number of Stems, NR: Number of Roots, NL: Number of Leaves, FB: Fresh Biomass, DB: Dry Biomass, W100g: Weight of 100 seed, NP: Number of Pods, SY: Soybean Seed Yield; NN: Number of Nodules

\begin{tabular}{|c|c|c|c|c|c|c|c|c|c|c|c|}
\hline & LR & $\mathrm{CD}$ & $\mathrm{PH}$ & NS & NR & $\mathrm{NL}$ & FB & DB & $\mathrm{W} 100 \mathrm{~g}$ & NP & SY \\
\hline$\overline{C D}$ & -0.24 & & & & & & & & & & \\
\hline $\mathrm{TH}$ & -0.13 & $0.59 * * *$ & & & & & & & & & \\
\hline NS & -0.04 & $0.74 * * *$ & $0.72 * * *$ & & & & & & & & \\
\hline NR & -0.04 & $0.55 * * *$ & $0.36^{*}$ & $0.71 * * *$ & & & & & & & \\
\hline NL & $-0.49 * *$ & -0.02 & 0.22 & 0.23 & -0.03 & & & & & & \\
\hline FB & 0.07 & $0.72 * * *$ & $0.72 * * *$ & $0.97 * * *$ & $0.74 * * *$ & 0.27 & & & & & \\
\hline DB & 0.09 & -0.17 & -0.03 & -0.08 & 0.04 & 0.06 & -0.07 & & & & \\
\hline W100g & $-0.35^{*}$ & $0.40^{* *}$ & 0.29 & 0.21 & 0.14 & $-0.40 * *$ & 0.19 & -0.06 & & & \\
\hline NP & $0.47 * *$ & 0.01 & 0.19 & 0.21 & -0.14 & $0.72 * * *$ & 0.23 & 0.14 & -0.14 & & \\
\hline SY & $0.35^{*}$ & $0.34 *$ & $0.41 * *$ & $0.32 *$ & 0.11 & $0.48 * *$ & $0.42 * *$ & -0.07 & 0.20 & $0.48^{* *}$ & \\
\hline NN & 0.05 & 0.14 & 0.29 & 0.25 & 0.05 & 0.19 & 0.24 & -0.01 & 0.22 & $0.33^{*}$ & $0.43 * *$ \\
\hline
\end{tabular}

*Significant at $\mathrm{p} \leq 0.05 ; * *$ Significant at $\mathrm{p} \leq 0.01 ; * * *$ Significant at $\mathrm{p} \leq 0.001$

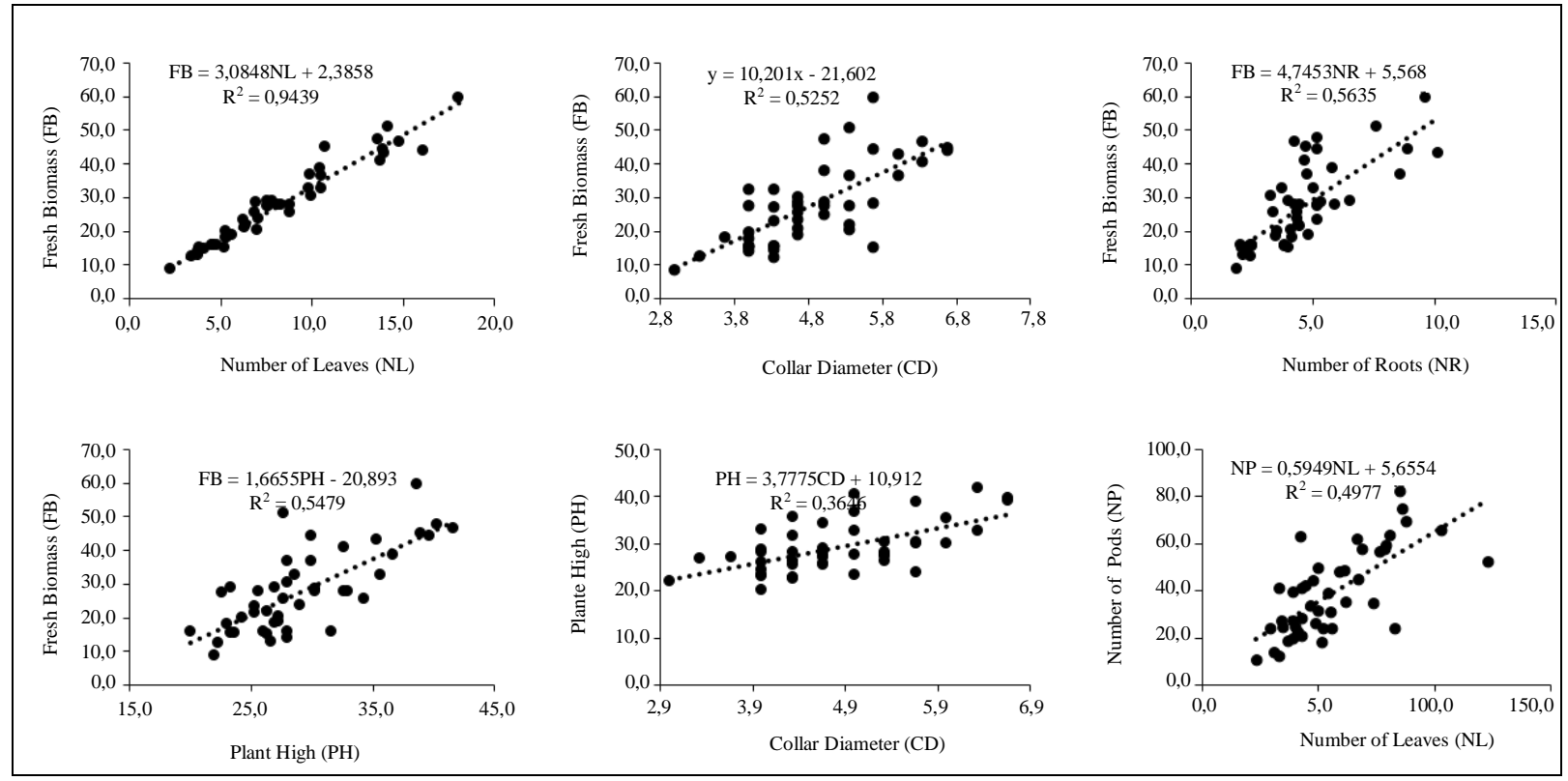

Fig. 1: Linear regression between different soybean growth parameters

A negative correlation is observed between NF and $\mathrm{P} 100 \mathrm{~g}$ indicating that if the value of one of this parameter increases, the other decreases. The same observation is made between LR and NL, LR and $\mathrm{W} 100 \mathrm{~g}$. The results also show that NP and CD are completely independent, the two parameters are not dependent in this study. This concerns all correlations whose value is close to 0 .

Figure 1 shows the linear regressions between different soybean growth parameters. As a result, Fresh Biomass (FB) is the most predictable parameter in this study. However, leaf number (NL) is the growth parameter that contributes most to soybean FB. The prediction power indicates that $94 \%$ of the $\mathrm{FB}$ is explained by the NL. This implies that only $6 \%$ of the variance of the FB is not explained by the NL. Another parameter explaining the FB is the Collar Diameter
(CD). This agronomic parameter contributes for more than $52 \%$ to $\mathrm{FB}$, with about $48 \%$ of the variance of the parameter not explained by the $\mathrm{CD}$. Moreover, the influence of the number of roots (NR) on the biomass is greater than that of the $\mathrm{CD}$. Indeed, the regression coefficient obtained is 0.56 . What implies the NR strongly explains the FB and is an important predictor. As for Plant High (PH), observations show that this parameter strongly influences $\mathrm{FB}$, with a regression coefficient of ca. 0.54. This prediction power of the $\mathrm{PH}$ is associated with those of NL, CD and NR. These observations imply that improving the performance of these parameters is an effective way to increase soybean FB.

Moreover, $\mathrm{PH}$ being a predictor for $\mathrm{FB}$ is itself explained at $36 \%$ by the $\mathrm{CD}$. Indeed, the $\mathrm{CD}$ contributes not only to FB but also the PH. Nevertheless, its contribution on the FB is much higher than that on the $\mathrm{PH}$. 
Concerning NL, a most important agronomic parameter of FB, the result indicates that this parameter also explains the Number of Pods (NP) obtained in this study. Indeed, the NP is explained to ca. $50 \%$ by the NL. Which implies that any increase in NL is an effective way to increase the number of soybean pods.

Figure 2 shows soybean agronomic parameters that effectively contribute to the crop yield. Indeed, among the agronomic parameters examined, four contribute directly to soybean yield, namely NL, NP, FB and CD. Although the predictive power of all these parameters is less than $25 \%$ while increasing their value would explain the yield of soybeans.

For NL, the regression coefficient obtained is 0.22 , the increase in NP contributes $20 \%$ to soybean yield, whereas, the $\mathrm{CD}$ has a predictive power of $12 \%$. FB, a most predictable parameter, appears to be unrelated to soybean yield in this study. The regression coefficient indicates that FB contributes only $4 \%$ to soybean SY.

Figure 3 shows the correlations between soybean growth and yield parameters on the one hand and the influence of the Bradyrhizobium japonicum and variety effect on these correlations on the other. This principle component analysis (ACP) provides $45 \%$ of the information on axis 1 and $25 \%$ on axis 2 , which represents $70 \%$ of information for the entire projection. For the axis 1 , the most explanatory variables are the different treatments T6, T10, T9, T7, T11, T14, T13, $\mathrm{T} 12$ and T15. However, the most explicative variables of axis 2 are both the growth and yield parameters of soybean and other treatments including T5, T8, T2, T3 and T4 while T16 is strongly correlated to both axes. NR, CD and W100g are strongly correlated to each other and with axis 1 , which implies that they are positively influenced by T16, T6, T14, T13 and T15 while being negatively influenced by T11, T7, T12, T9 and T10.

The DB, NN, SY and NR are strongly correlated to each other and to axis 2. This implies that these parameters are positively influenced by T16, T3 and T4 while being negatively influenced by $\mathrm{T} 5$ and $\mathrm{T} 8$. In addition, the results show that inoculum supply is an important factor that positively influences soybean growth and yield parameters. Indeed, in the absence of the inoculum, the different treatments negatively influence the growth and yield parameters of soya except for T13 which is positively correlated with axis 1 . This implies T13 (control) positively influences NR, CD and $\mathrm{W} 100 \mathrm{~g}$ while T5 and T9 are negatively correlated to axis 1 and axis respectively. T5 then negatively influences DB, NN, SY, NR, CD and P100g while T9 is negatively correlated to NR, CD and P100g. Positively correlated treatments are similar in terms of their influence on soybean growth and yield parameters.

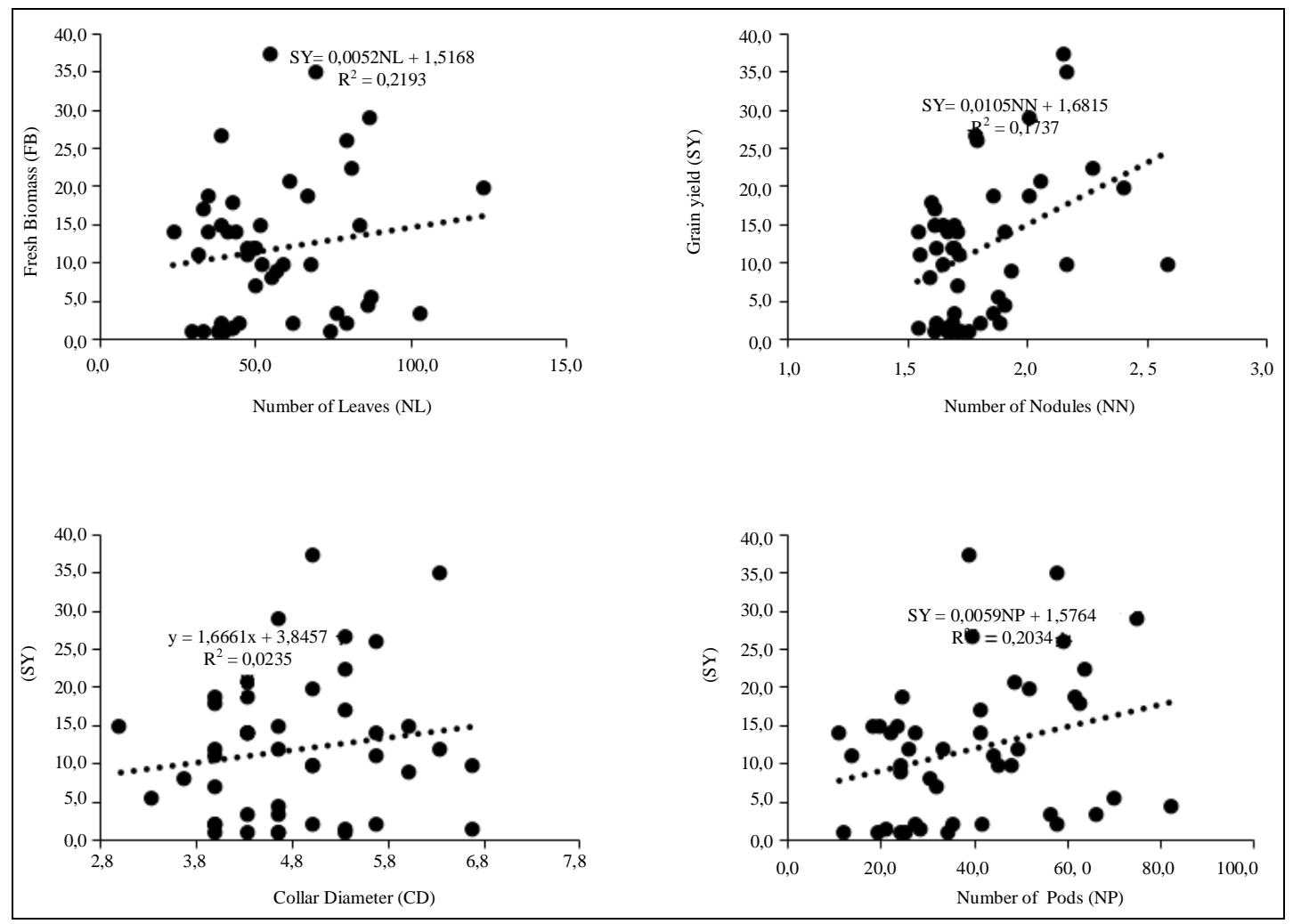

Fig. 2: Regression between some growth parameters and soybean yield 


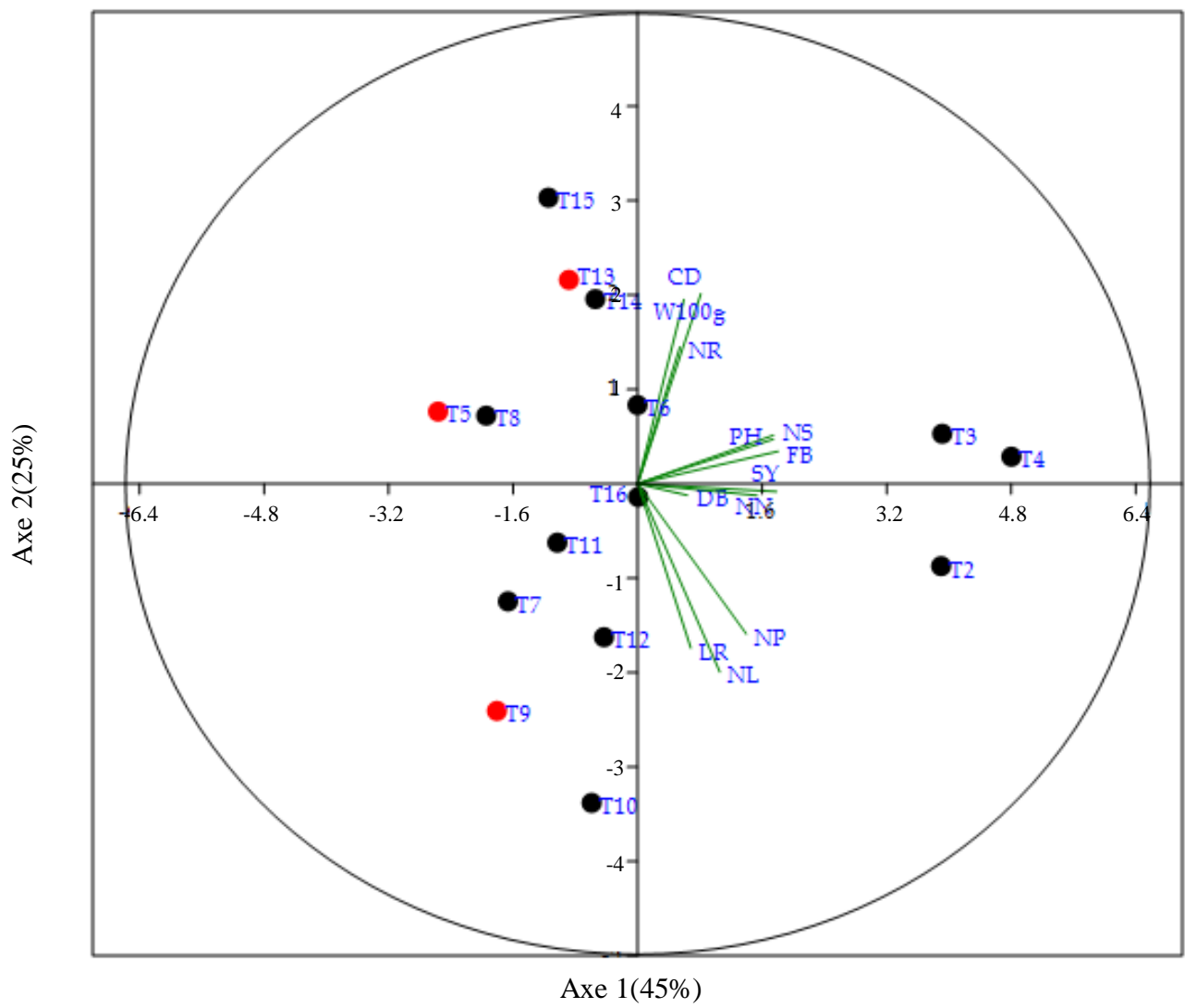

Fig. 3: Influence of inoculation on the correlations between growth and soybean yield parameters. T2: S1V1, T3: S2V1, T4: S3V1, T5: S0V2, T6: S1V2, T7: S2V2, T: S3V2, T9: S0V3, T10: S1V3, T11: S2V3, T12: S3V3, T13: S0V4, T14: S1V4, T15: S2V4, T16: S3V4

\section{Discussion}

In this study, the strongest correlations are obtained between FB and PH, NS and CD, FB and CD, NS and $\mathrm{PH}, \mathrm{NR}$ and NS, FB and NR, NP and NL. This implies that the value increase of one of this parameter leads to an increase in the parameter to which it is significantly correlated (Malik et al., 2011). Indeed, the positive link between this parameter is an important indicator in the conduct of the soybean crop. From obtained results, the $\mathrm{CD}$ is the most positively correlated to both growth and yield parameters of soybean. While the parameters the most correlated to SY are LR, CD, PH, NS, NL, FB, NN and NP. Significant and positive correlations between SY and these parameters were reported by Karnwal and Singh (2009; Mehmet et al., 2009; Maria et al., 2009; Benedict and Uguru, 2011; Malik et al., 2011; Machikowa and Laosuwan, 2011; El-Badawy and Mehasen, 2012; Sarutayophat, 2012; Chandel et al., 2014) and Atanda et al. (2014). This implies that poor development of each parameter positively correlated to SY would negatively impact crop productivity.

Moreover, the negative correlation observed between $\mathrm{NL}$ and W100g indicates that if the value of one of this parameter increases, the other decreases. In this context, the NL is the explanatory variable whereas $\mathrm{W} 100 \mathrm{~g}$ is the explained variable. The fact that an increase in NL that is not necessarily accompanied by efficient translocation of nutrients in seeds could explain this negative correlation. A large increase in NL implies a high utilization of the reproductive energy of the plant, which would limit the amount of energy intended for good seed formation. Other authors have found positive correlations between NL and W100g and explained this by the fact that the strong development of leaf biomass favors a strong interception of light which would result in a high photosynthetic efficiency and better formation of seeds (Kumar et al., 2000; Subhani et al., 2000; Esmail, 2003; Singh et al., 2006; Bilgi, 2006). The observations made in this study would be attributed to environmental conditions that did not favor the synergy between NL and W100g. The results also showed that NP and CD are totally independent, the two parameters are not correlated in this study. This would indicate that regardless of the NP, this cannot be directly attributed to the CD.

Despite the fact that correlations provide necessary information on the types of linkages between variables, the meaning of the link and its quantification are not 
clearly defined (Guler et al., 2001; Ulukan et al., 2003; Garcia del Moral et al., 2005). It is thus important to use linear regression between an explanatory variable and an explained variable in order to quantify the extent of the contribution (Chandel et al., 2014). This study showed that FB is the most predictable parameter whereas the $\mathrm{NL}$ is the growth parameter that contributes the most to soybean FB. Since FB is directly linked to the vegetative growth of the plant, it makes sense that any better expression of the growth parameters (mainly NL) contributes to the increase of its value. The more leaves there are in a plant, the higher its $\mathrm{FB}$, because in soybean, for example, NL, NR and NS are the main components of FB. Another parameter explaining the FB is $\mathrm{CD}$. This agronomic parameter contributes more than $52 \%$ to $\mathrm{FB}$, with about $48 \%$ of the variance of the parameter not explained by the $\mathrm{CD}$. Larger organs can store more carbohydrate stores, which are used by young plants at the beginning of the growing period (Chandel et al., 2014). Based on their decreasing contribution on the FB, the various parameters can be classified as follows: $\mathrm{NL}>\mathrm{NR}>\mathrm{PH}>\mathrm{CD}$. This succession shows the most determinant parameters on FB.

For NL, a most important agronomic parameter of $\mathrm{FB}$, the result indicates that this parameter contributes strongly to pod formation. Indeed, the NP obtained is explained to approximately $50 \%$ by the NL. Which implies any increase in NL is an effective way to increase the number of soybean pods. This is explained by the role played by leaves through photosynthesis, which would have favoured the formation of pods while disadvantaging the weight of seeds inside the pods. This paradox would be the result of the combination of the genotype and edapho-climatic conditions during the experiment.

Among the agronomic parameters examined, only four contribute directly to the yield of soybeans, NL, NP, FB and CD. Although, the predictive power of these parameters is less than $25 \%$, increasing their value would explain the yield of soybeans. Based on their decreasing contribution, these parameters can be classified as follows: NL> NP>CD> FB. The influence of NL and NP on SY has been reported by several authors (Khan et al., 2000; Mellendorf, 2011). The NL is a parameter that determines the photosynthetic efficiency of a plant and consequently its performance on SY. However, it is influenced by several factors including the environment (Talebi et al., 2010; Mbarek et al., 2012; Chandel et al. 2014; Mbah and Eke-Okoro, 2015). Furthermore, NP is one of the most important yield parameters that determine the number of seeds per plant. As for the CD, its contribution to SY would be linked to the fact that more plants are vigorous, more energy is available to be allocated to SY. The FB, a most predictable parameter, appears to be unrelated to soybean yield in this study. The regression coefficient indicates that FB contributes only $4 \%$ to SY. This would be the proof that good vegetative growth is not always synonymous of high grain yield.

By applying Bradyrhizobium japonicum to four soybean varieties, the results showed that correlations between observed parameters were strengthened. Indeed, in the absence of the inoculum, the different treatments negatively influence the soybean growth and yield parameters except for T13 which is positively correlated to NR. These observations would be a major indicator of the importance of inoculation in soybean cultivation since, without soybean inoculum, soybean performance is compromised on several parameters. Positively correlated treatments are similar in terms of their influence on soybean growth and yield parameters. These similarities between treatments are the result of genetic factors of the varieties combined with environmental factors that define their expression (Ozveren Yucel et al., 2006; Talebi et al., 2010; Mbarek et al., 2012; Chandel et al., 2014; Mbah and Eke-Okoro, 2015).

\section{Conclusion}

This study aimed to evaluate the correlations between different agronomic parameters and their contribution to soybean performance under Bradyrhizobium japonicum influence. This study showed that some positive correlations are significant while others are not. The same observation is made for negative correlations. The strongest correlations are obtained between $\mathrm{FB}$ and $\mathrm{PH}$, NS and CD, FB and CD, NS and PH, NR and NS, FB and NR, NP and NL. This study also showed that FB is the most predictable parameter whereas the NL is the growth parameter that contributes the most to soybean FB. From the agronomic parameters examined, only four contribute directly to the yield of soybeans, NL, NP, FB and CD. However, their predictive power is low because it accounts for less than $25 \%$ of the obtained yield. By applying the Bradyrhizobium japonicum to four soybean varieties, the correlations between observed parameters were strengthened.

This study is a major contribution to the conduct of soybean cultivation as it has identified the parameters on which the farmers should focus to maximize the yield of fresh biomass or grain soybean. However, more experiments are needed in other areas of the province of Upper Katanga to highlight the agronomic parameters more sensitive to environmental conditions.

\section{Acknowledgement}

The authors acknowledge the technical and/ or financial support from CIAT, HarvestPlus, the University of Lubumbashi as well as technicians from INERA or development partners and farmers who participated and/or funded the implementation of this research. 


\section{Author's Contribution}

Ben Tshibuyi Kasu-Bandi: Contributed in paper preparation, development and publication.

Laurent Kidinda Kidinda: Contributed in paper preparation, developement and publication

Germain Nyembo Kasendue: Contributed in paper preparation and development

Louis Baboy Longanza: Contributed in paper development

Kasongo Lenge Emery: Contributed in paper preparation and development

Antoine Kanyenga Lubobo: Contributed in paper preparation and development

\section{Ethics}

Authors declare that there not any conflit of interest or any other ethical issues that may arise after the publication of this manuscript. All date are original from experiments conducted by the Authors of this manuscript.

\section{References}

Abaidoo, R.C., H.H. Keyser, P.W. Singleton, K.E. Dashiell and N. Sanginga, 2007. Population size, distribution and symbiotic characteristics of indeginous Bradyrhizobium spp. that nodulate TGx soybean genotypes in Africa. Applied Soil Ecology, 35: 57-67.

Amanullah and M. Hatam, 2001. Performance of AVRDC vegetable soybean germplasm under Peshawar valley conditions [Pakistan]. Sarhad J. Agric., 17: 27-30.

Amin, F., Z. Fatima, M. Zia and M.F. Chaudhary, 2008. Interactive effect of Rhizobium strains and $\mathrm{P}$ on soybean yield, nitrogen fixation and soil fertility. Pak J. Bot., 39: 255-264.

Atanda, S., A.I. Afe, M.O. Aduloju and S.K. Ogundare, 2014. Evaluation of some morphological and yield component traits relationship to soybean seed yield. J. Biology Agric. Healthcare.

Baboy, L.L., K.L. Kidinda, K.M. Kilumba, S. Langunu and K.M. Mazinga et al., 2015. Influence of seedlings late on the growth and the yield of soybean(Glycine max Merril) cultivated under different gauges to Lubumbashi, RD Congo. Int. J. Innovation Applied Studies, 12: 104-109.

Benedict, C.O. and M. Uguru, 2011. Interrelationships among Pod and Seed Yield Traits in Bambara Groundnut (Vigna subterranea L. Verdc) in the Derived Savanna Agro-Ecology of South-Eastern Nigeria under Two Planting Dates. Int. J. Plant Breeding, 5: 106-111.

Bilgi, S.A., 2006. Physiological investigations in dicoccum wheat genotypes. M. Sc. Thesis University of Agricultural Sciences Dharwad. pp: 1-76.
Bruno, J.R., R. Alves, M. Boddey and U. Segundo, 2003. The success of BNF in soybean in Brazil. Plant Soil, 252: 1-9. DOI: $10.1023 / \mathrm{A}: 1024191913296$

Chandel, K.K., N.B. Patel and J.B. Patel, 2014. correlation coefficients and path analysis in soybean (Glycine max L. MERRILL). AGRES Int. J., 3: 25-31.

El-Badawy, M.E.M. and S.A.S. Mehasen, 2012. Correlation and path coefficient analysis for yield and yield components of soybean genotypes under different planting density. Asian J. Crop Sci., 4: 150-158. DOI: 10.3923/ajcs.2012.150.158

Esmail, R.M., 2003. Correlation and path-coefficient analysis of some quantitative traits with grai yield in bread wheat (Triticum aestivum L.) Bulletin of the National Centre. Cairo, 26: 395-408.

FAO, 2017. Statistical programme of work. Food and Agriculture Organiszation of the United States, pp: 72.

Fatima, Z., M. Zia and M.F. Chaudhary, 2007. Effect of Rhizobium strains and phosphorus on growth of soybean (Glycine max) and survival of Rhizobium and P solubilizing bacteria. Pak. J. Bot., 38: 459-464.

Ferguson, R.B., C.A. Shapiro, A.R. Dobermann and C.S. Wortmann, 2006. Fertilizer recommendations for soybeans. [En ligne]. Institute of Agriculture and Natural Resources.

Garcia del Moral, L.F., Y. Rharrabti, S. Elhani, V. Martos and C. Royo, 2005. Yield formation in Mediterranean durum wheat under two contrasting water regimes based on path coefficient analysis. Euphytica, 146: 203-212.

DOI: 10.1007/s10681-005-9006-2

Giller, K.E. and Dashiell, 2007. Glycine $\max$ (L) Merill. Sheet protobase, In: Plant resources of Tropical Africa. (PROTA), Van der Vossen, H.A.M. and G.S. Mkamilo, (Eds.), Wageningen, Pays Bas.

Graham, P.H. and C.P. Vance, 2003. Legumes importance and constraints to greater utilization to greater utilization. Plant Physiology, 131: 872-877.

Guler, M., M.S. Adak and H. Ulukan, 2001. Determining relationships among yield and some yield components using path coefficient analysis in chickpea (Cicer arietinum L.). Eur. J. Agronomy, 4: 161-166.

Hardarson, G. and C. Atkins, 2003. Optimising biological N2 fixation by legumes in farming systems. Plant Soil, 252: 41-54.

Hungry, S. and F. Bohrer, 2000. Influence of nitrogen fixing and phosphorus solubilizing bacteria on the nodulation, plant growth and yield of chickpea. J. Plant Nutr., 31: 157-171.

Javaheri, F. and J.P. Baudoin, 2001. Le soja. In: Agriculture en Afrique Tropical (Directorate General for International Cooperation), Raemaerkers R.H. (Ed.), Ministry of Foreign Affairs, External Trade and International Cooperation, Brussels, Belgium, pp: 860-882. 
Karnwal, M.K. and K. Singh, 2009. Studies on genetic variability, character association and path coefficient for seed yield and its contributing traits in soybean (Glycine max L. Merrill.). Legume Res., 32: 70-73.

Kasongo, L.E, M.T. Mwamba, M.J. Mukalay, S.Y. Useni and K.M. Mazinga et al., 2013. Answer of culture of soybean (Glycine max L. (Merril) to contribution of biomass green of Tithonia diversifolia (Hemsley) A. Gray as manure organic on one Ferralsol to Lubumbashi, R.D. Congo. J. Applied Biosci., 63: 4727-4735.

Khan, S., A. Latif, S.Q. Ahmad, F. Ahmad and M. Fida, 2011. Genetic variability analysis in some advanced lines of soybean (Glycine max L.). Asian J. Agric. Sci., 3: 138-141.

Kumar, A., R.S. Verma and S.B. Samdarshi, 2000. Correlation studies on yield and yield attributes of wheat (Triticum aestivum). Gujarat Agricultural University Res. J., 25: 5-8.

Kumar, M.P., B. Bharat, N.B. Hari, N.S. Bhupendra and K. Arun, 2013. Analysis of yield components and their association for enhancing grain yield in bread wheat (Triticum aestivum L. em Thell.) under salinesodicity reclaimed condition, J. Wheat Res., 5: 35-38.

Kuswantoro, H., 2014. Potential yield of Soybean lines are higher than their parent Indonesian lowland popular variety, Int. J. Biology.

Machikowa, T. and P. Laosuwan, 2011. Path coefficient analysis for yield of early maturing soybean. Songklanakarin J. Sci. Technol., 33: 365-368.

Malik, M.F.A., M. Ashraf, A.S. Qureshi and M.R. Khan, 2011. Investigation and comparison of some morphological traits of the soybean populations using cluster analysis. Pak. J. Bot., 43: 1249-1255.

Mandimba, G.R., 1997. L'inoculation: on weapon against the hunger in the country in development. Laboratory of Biotechnology. Institute of Dévelopment Rural. Congo.

Maria, A., A. Martin Eugenia, V.P. Cravero, D. Liberrato and A. Lopex et al., 2009. Relationships among agronomic traits and seed yield in pea. Bag. J. Basic Applied Genetics, Ciudad Autonoma de Buenos Aires ene.

Mbah, E.U. and O. Eke-Okoro, 2015. Relationship between some growth parameters, dry matter content and yield of some sweet potato genotypes grown under rainfed weathered ultisols in the humid tropics. J. Agronomy, 14: 121-129.

Mbarek, K.B., M. Boubaker and C. Hannachi, 2012. Modéling of yield grain of chickpea(Cicer arietinum L.) of type «kabuli » under the conditions édaphoclimatiques du semi-arid supérior Tunisian. Rev. Mar. Sci. Agron. Vét., 2: 37-49.

Mehmet, O.Z., A.A. Karasu, T. Goksoy and Z.M. Turan, 2009. Interrelationships of agronomical characteristics in soybean (Glycine max) grown in different environments. Intl. J. Agric. Biol., 11: 85-88.
Mellendorf, N.E., 2011. Soybean growth and yield response to interplant competition relief in various plant density environments. MSc Thesis, University of Illinois at Urbana-Champaign, Illinois.

Moulaert, N., 1992. Emissions of industry métallurgy to Lubumbashi (Shaba-Zaïre) and conséquences on the environment. Mémory, Faculty of Sciences Agronomic of Gembloux/ Belgique.

Mukalay, M.H.J., 2016. Identification and classification of soil under the news stantards and study of bioidentification and of restoration of units gradient in the zone agricultural of top-Katanga/RD-Congo, Thesis of Doctorate, Université of Lubumbashi.

Ozveren, Y. D., A.E. Anlarsal and C. Yûcel, 2006. Genetic variability, correlation and path analysis of yield and yield components in chickpea (Cicer arietinum L.). Turk J. Agric. For, 30: 183-188.

Panda, D., A. Sen, D.S. Dhakre and S. Mondal, 2015. correlation analysis of some growth, physiological parameters, yield and yield attributes of chick pea (Cicer arietinum L.), Int. J. Bio-res. Env. Agril. Sci., 1: 90-95,2015.

Peluzio, J.M., R.D. de-Almeida, R.R. Fidelis, D. Almeida-Jr. and E.L. Brito et al., 2005. Correlations among traits of soybean, in Gurupi, Tocantins. Rev. Ceres., 52: 779-786.

Sarutayophat, T., 2012. Correlation and path coefficient analysis for yield and its components in vegetable soybean. Songklanakarin J.

Singh, K.N., N. Kulshreshtha, V. Kumar and S. Tim, 2006. Genetic variability of wheat (Triticum aestivum L.) lines for grain yield and components characters grown under sodic and water logged condition. Indian J. Agric. Sci., 76: 414-19.

Sokoto, M.B., I.U. Abubakar and A.U. Dikko, 2012. Correlation analysis of some growth, yield, yield components and grain quality of wheat (Triticum aestivum L.). Nigerian J. Basic Applied Sci., 20: 349-356.

Subhani, G.M. and M.A. Chowhdry, 2000. Correlation and path coefficient analysis in bread wheat under drought stress and normal conditions. Pakistan J. Biol. Sci., 3: 72-77.

Talebi, R., F. Farzad and M.N. Amir, 2010. Genetic variation and interrelationships of agronomic characteristics in durum wheat under two constructing water regimes. Braz. Arch. Biol. Technol. 53: 785-791.

Tshibuyi, K.B.B. and K.L. Kidinda, 2015. Assessment of combined effects of human faeces and mineral fertilizers on the behavior of Okra (Abelmoschus esculentus L.) Cultivated in Lubumbashi, DR Congo. Am. J. Plant Nutrition Fertilization Technology, 5: 106-112. 
Ben Tshibuyi Kasu-Band et al. / American Journal of Agricultural and Biological Sciences 2019, Volume 14: 86.94 DOI: 10.3844/ajabssp.2019.86.94

Ulukan, H., M. Guler and S.D.D.K. Keskin, 2003. A path coefficient analysis some yield and yield components in faba bean (Vicia faba L.) genotypes. Pakistan J. Biol. Sci., 6: 1951-1955.
WRB, 2014. World reference base for soil resources. International Soil Classification System for Naming Soils and Creating Legends for Soil Maps, pp: 203. 